\title{
EDUCAÇÃO DOMICILIAR COMO PROTECIONISMO RACIAL NOS ESTADOS UNIDOS*
}

Ama Mazama**

\begin{abstract}
Resumo: Embora a educação domiciliar esteja aumentando consideravelmente na comunidade negra dos Estados Unidos, as pesquisas sobre as motivações dos pais negros que escolhem educar seus filhos em casa são raras. De fato, os pesquisadores parecem supor que o desligamento dos afro-americanos do sistema escolar é ditado por razões similares àquelas citadas pelos brancos. Muitas vezes, os pesquisadores eurocêntricos negam que os africanos sejam capazes de avaliar seus problemas e sejam incapazes de tomar iniciativas para encontrar soluções para eles. É como se tudo que os negros pudessem fazer fosse simplesmente imitar os brancos cuja experiência é considerada universal. No entanto, a experiência e a voz únicas dos afro-americanos devem ser levadas em conta se realmente quisermos entender por que mais e mais negros não mandam seus filhos para a escola. Neste ensaio, eu exploro três das principais razões pelas quais os afro-americanos estão cada vez mais escolhendo educar seus filhos em casa, a saber: o racismo branco e seu impacto devastador sobre as crianças africanas; a insatisfação com a baixa qualidade da educação; e a desintegração dos laços familiares sob o impacto da escolaridade. Este estudo é baseado em entrevistas com 74 famílias negras que educam seus filhos em casa nos Estados Unidos.
\end{abstract}

Palavras-chave: Educação domiciliar; Afro-americanos; Racismo; Vida familiar; Qualidade da educação

Resumen: Aunque la educación domiciliaria está aumentando considerablemente en la comunidad negra de Estados Unidos, las investigaciones sobre las motivaciones de los padres negros que eligen educar a sus hijos en casa son raras. De hecho, los investigadores parecen suponer que el cierre de los afroamericanos del sistema escolar es dictado por razones similares a aquellas citadas por los blancos. Muchas veces, los investigadores eurocéntricos niegan que los africanos sean capaces de evaluar sus problemas y sean incapaces de tomar iniciativas para encontrar soluciones para ellos. Es como si todo lo que los negros pudieran hacer es simplemente imitar a los blancos cuya experiencia se considera universal. Sin embargo, la experiencia y la voz únicas de los afroamericanos deben ser tenidas en cuenta si realmente queremos entender por qué más y más negros no mandan a sus hijos a la escuela. En este ensayo, explotan tres de las principales razones por las que los afroamericanos están eligiendo cada vez más para educar a sus hijos en casa, a saber: el racismo blanco y su impacto devastador sobre los niños africanos; la insatisfacción con la baja calidad de la educación; y la desintegración de los vínculos familiares bajo el impacto de la escolaridad. Este estudio se basa en entrevistas con 74 familias negras que educan a sus hijos en casa en Estados Unidos.

Palabras clave: Educación en el hogar; Afroamericanos; Racismo; Vida familiar; Calidad de la educación

\section{Introdução}

\footnotetext{
${ }^{*}$ Artigo escrito para o Dossiê Educação, Filosofia e Afrocentricidade. Tradução realizada por Ricardo Matheus Benedicto Professor do Instituto de Humanidades e Letras - Malês da Unilab, Coordenador do Curso de Pedagogia e Coordenador do Grupo de Pesquisa em Educação Afrocentrada. E-mail: ricardomb@unilab.edu.br.
}

Nos Estados Unidos, o interesse dos acadêmicos pela educação domiciliar aumentou nos últimos anos, porque embora tenha sido percebida como um desenvolvi-

\footnotetext{
** Professora e Diretora de Estudos de Graduação do Departamento de Africologia e Estudos Afroamericanos da Universidade de Temple. E-mail: MCerol@temple.edu.
}

MAZAMA, Ama. Educação domiciliar como protecionismo racial nos Estados Unidos. Revista SulAmericana de Filosofia e Educação. Número 31: mai.-out./2019, p. 34-52. DOI: https://doi.org/10.26512/resafe.vi3o.28255 
mento marginal, a educação domiciliar tornou-se, de fato, um fenômeno importante e tem aumentando de forma constante. $\mathrm{Na}$ verdade, estima-se que cerca de 2 milhões crianças estão sendo educadas atualmente em casa nos Estados Unidos, em comparação com as 300.000 em 1990, indicando um aumento espetacular ao longo de um período relativamente curto de tempo. Embora os estudantes brancos ainda representarem aproximadamente $75 \%$ das crianças educadas em casa, a participação dos afroamericanos neste movimento é cada vez mais destacada. Em 1999, estimava-se que quase $10 \%$ de todas as crianças educadas em casa eram negras, e esses números parecem estar aumentando.

No entanto, pesquisas sobre as motivações dos pais negros que optam por educar seus filhos em casa são escassas. A suposição implícita parece ser a de que a retirada dos afro-americanos do sistema escolar é ditada por razões semelhantes às dos brancos. Como muitas vezes, os pesquisadores eurocêntricos negam que os africanos demonstrem iniciativas que são do seu interesse, é como se tudo o que os negros pudessem fazer é simplesmente imitar os brancos cuja experiência é considerada universal. No entanto, a experiência e voz únicas dos afro-americanos devem ser levadas em conta se realmente quisermos entender por que mais e mais pessoas negras não enviam seus filhos para a escola.

O objetivo deste artigo é, portanto, explorar três das principais razões pelas quais os afro-americanos estão cada vez mais escolhendo educar seus filhos em casa, a saber: o racismo branco e seu impacto devastador em crianças africanas; a insatis- fação com a má qualidade da educação; e a desintegração dos laços familiares sob o impacto da escolaridade.

Permitam-me indicar desde o início que não tentarei ser "objetiva" ou "neutra". Não só a objetividade e a neutralidade epistêmica são insustentáveis, mas eu mesma estou envolvida neste fenômeno da educação domiciliar com meus três filhos há quase 16 anos.

Tudo começou, por assim dizer, quando o meu filho mais velho, então com 7 anos de idade, viu-se confrontado com uma professora (negra) completamente inepta. Embora a escola seja afrocêntrica (eu nunca teria enviado meu filho para uma escola não-afrocêntrica), a professora não era, visto que reduzia seu ensino sobre a África a uma série de slogans vazios que mal escondia sua ignorância. Além disso, ela insistiu em reproduzir na escola afrocêntrica em questão o modelo de funcionamento das escolas públicas dos Estados Unidos. Este modelo é baseado na noção de que os alunos devem ser testados continuamente, pois as escolas devem demonstrar que têm um bom desempenho. Isto é particularmente verdadeiro, no caso do programa de Bush "Nenhuma Criança Deixada Para Trás", que foi criado supostamente pelo fato que o sistema escolar americano estava tornando-se cada vez mais incapaz de assegurar mesmo um mínimo da formação intelectual para estudantes da escola pública (90\% das crianças nos Estados Unidos frequentam escolas públicas). De fato, muitos foram/são aqueles que, mesmo depois de muitos anos trancados em salas de aula não sabiam/sabem ler ou contar fluentemente. A professora do meu filho, portanto, aplicou 
provas ad-nauseam para seus alunos e, de fato, o objetivo não era aprender nada, mas memorizar coisas que ele não necessariamente entendia, a fim de vomitá-las no exame e ter um "A". Esta nota deveria indicar que ele tinha aprendido alguma coisa. A medida que o ano avançou, os controles tornaram-se cada vez mais numerosos, com um mínimo de 10 verificações por semana para crianças de 7-8 anos... E com o passar do tempo, meu filho sendo submetido a este regime absurdo, vi que a luz que brilhava profundamente em seus olhos, a luz que o levava fazer perguntas sobre tudo, a ponto de ser apelidado de "Sr. Por quê?", estava desaparecendo de modo lento e certo. Meu filho estava em processo de zumbificação. Ele que adorava ler, aprender, fazer perguntas, compreender, não queria saber de nada. Eu podia compreendê-lo por que eu mesma o preparei para os seus exames, e estava exasperada e exausta mental e fisicamente. Era tortura e teria repugnado qualquer um. Depois de engolir nossa refeição rapidamente, passávamos todas as noites nos preparando para as avaliações do dia seguinte. Nossa vida familiar foi reduzida ao mínimo, e como não nos víamos durante o dia da hora que o deixava na escola - a partir de 8 horas da manhã - até a hora de buscá-lo entre 17 e 18 horas, desnecessário dizer que tínhamos cada vez menos oportunidades para compartilhar verdadeiramente, ou fazer qualquer coisa realmente interessante ou importante juntos. Apenas na noite de sexta-feira que tínhamos algum tempo, mas estávamos tão exaustos pela semana que acabamos de passar, privados de sono, e já preocupados com os controles da próxima semana, que tínhamos pouca energia para fazer qualquer coisa, para dizer a verdade.

Era para proteger a luz que brilhava no fundo dos olhos do meu filho que eu decidi não mandá-lo de volta para a escola no ano seguinte, mas mantê-lo em casa. Eu não sabia na época, mas ele ia se juntar às fileiras das 200.000 crianças negras que não vão para a escola nos Estados Unidos.

As minhas motivações colocaram-me na categoria de pais insatisfeitos com a qualidade da educação prestada pela escola. Estas motivações não são necessariamente as de todos os pais. Eu também não sabia disso.

Foi somente quando comecei a fazer uma pesquisa sistemática sobre o que é chamado nos Estados Unidos "Homeschooling" que gradualmente tomei consciência da magnitude crescente deste fenômeno e da aparente diversidade das motivações dos pais negros que decidem educar seus filhos em casa.

O que eu gostaria de compartilhar nas páginas seguintes são os resultados da minha pesquisa sobre educação domiciliar nos Estados Unidos, e mais especificamente, sobre as motivações dos pais negros que fizeram a escolha de não enviar seus filhos para a escola. Embora o quadro social americano possa ser diferente do quadro vigente no Brasil, os desafios que os pais negros enfrentam quando seus filhos têm que ir para a escola não são necessariamente diferentes. Todos nós somos confrontados, por exemplo, com a questão dos programas educativos que não levam suficiente ou adequadamente em conta a nossa cultura e história. $\mathrm{Na}$ verdade, nossos filhos, onde quer que estejam, parecem sofrer lavagem cerebral 
que os tornam ignorantes ${ }^{2}$ ou desdenhoso de si mesmos e de suas tradições ancestrais. É neste sentido que a experiência das irmãs e irmãos afro-americanos traz ensinamentos valiosos. Como tem sido frequentemente o caso, os africanos nos Estados Unidos estão vários passos à frente quando se trata de analisar e combater o monstro racista branco. É que eles vivem no ventre da besta por assim dizer e não podem se dar ao luxo, como é muitas vezes o caso em outros lugares, de negar as intenções brancas altamente maliciosas e destrutivas em nosso lugar. A crueldade e brutalidade branca e sua determinação para impedir que os negros nos Estados Unidos vivam em paz são tão constantes e óbvias que os pais negros não têm escolha senão se organizar para proteger seus filhos da melhor forma possível. A educação domiciliar é certamente uma das estratégias mais recentes de proteção adotadas por um número crescente de pais negros nos Estados Unidos.

Em 2010 e 2011, viajei várias regiões dos Estados Unidos para interrogar 74 famílias negras que haviam feito essa escolha, a fim de lhes fazer duas perguntas simples: por que a educação em casa?, e como você procede?

Aqui, resumidas a seguir, as razões citadas e a sua frequência em percentagens:

\footnotetext{
${ }^{2}$ Como explicar, por exemplo, que até hoje, as crianças haitianas aprendemos na escola que há quatro estações no Haiti: outono, inverno, primavera e verão? Em um país tropical como o Haiti, isto é totalmente absurdo, mas tem o efeito de implicitamente colocar a Europa, e França, em particular, como uma norma. Igualmente tem o efeito de separar as crianças mentalmente de seu ambiente geográfico. Algumas vão passar o resto de suas vidas sonhando com a neve, e ser capaz de fazer bonecos de neve...
}

$\begin{array}{lc}\text { Racismo } & \mathbf{2 2 , 4} \\ \text { A qualidade da educação } & 19,6 \\ \text { Laços da família } & \mathbf{1 2 , 8} \\ \text { A religião } & 8,9 \\ \text { Problemas de segurança } & 7,1 \\ \text { Moralidade (não-religiosa) } & 3,9 \\ \text { Restrições financeiras } & 3,9 \\ \text { Demasiada lição de casa } & 3,9 \\ \text { Necessidades especiais } & 3,2 \\ \text { Outros } & 6,8\end{array}$

Concentrarei a análise, particularmente, nas três principais razões citadas, a saber, o racismo, qualidade da educação e laços familiares 3 .

\section{O racismo como o primeiro fator moti- vador}

Programas educacionais e preconceitos e as ações racistas dos professores e administradores brancos foram as duas principais fontes de insatisfação.

\section{A escola: um lugar perigoso}

Existe, antes de tudo, um consenso de que a escola é um lugar emocionalmente (e às vezes também fisicamente) perigoso para as crianças negras, um lugar onde elas são frequentemente humilhadas, e onde é simplesmente impossível para elas desenvolverem uma identidade racial e cultural positiva, porque a escola tenta impor a

\footnotetext{
3 Os leitores interessados em uma análise completa (de todas as motivações) devem obter o meu livro sobre o assunto, African American Homeschooling: Motivations, Opportunities and Challenges. Londres: Routledge. 2015.
} 
brancura nelas como a norma universal ideal.

De acordo com os pais com quem eu conversei sobre este assunto, não poderia ser de outra forma dada a natureza racista da sociedade americana. Levando em conta a afirmação de Malcolm X de que "apenas um tolo permitiria que seus inimigos ensinassem seus filhos", alguns pais formularam abertamente sua análise da dinâmica escolar em termos de guerra racial, escolas e professores brancos sendo descritos como "o inimigo". Pier, mãe de dois filhos, em Halifax (Virgínia), por exemplo, foi categórica: "por que eu deveria confiar meus filhos aos inimigos para educá-los?" Sentimentos semelhantes foram expressos por Joseph, pai de duas meninas, da Filadélfia: "não devemos permitir que as pessoas que historicamente nos oprimiram eduquem os nossos filhos, é ridículo... é estupidez. Por que eu permitiria que meu opressor ensinasse meu filho quem ele é, quem ele deveria ser?"

\section{A internalização das atitudes antinegras}

A opressão racial e a hostilidade enfrentadas por crianças negras na escola assumem muitas formas e têm múltiplas consequências. Uma delas é a internalização do racismo antinegro, fruto da propaganda antinegra que a escola implícita ou explicitamente reproduz. Na escola, as crianças negras recebem a mensagem de que ser negro significa ser inferior em todos os aspectos, cognitivo, cultural, estético, etc. Por exemplo, os livros didáticos aos quais estão expostos e a partir dos quais devem estudar estão sempre cheios de brancos (o que faz com que as crianças negras se identifiquem inconscientemente com eles), apresentados como conquistadores, pioneiros em tudo, tendo, por assim dizer, o monopólio da inteligência e da história. Suas preocupações e suas aventuras, tão banais e comuns devem preocupar e interessar a todos.

As poucas vezes em que os negros aparecem, eles estão frequentemente em uma posição subordinada, ou aparecem apenas porque os brancos intervieram em sua existência (por exemplo, durante a escravidão ou colonialismo). Em outras palavras, o que é apresentado aqui como autoevidente, mais uma vez, é a afirmação da superioridade branca, ou seja, uma historiografia eurocêntrica que coloca os brancos no centro da nossa história. Tudo começa sempre com eles. Antes deles não havia nada que merecesse ser estudado ou mencionado. Mas como nos lembra tão apropriadamente Molefi Asante, "uma sociedade racista só pode produzir uma escola racista."

Esta historiografia, bem como a notória ausência de negros em livros didáticos, transmite uma mensagem muito clara que não escapa às crianças: os negros não fizeram nada de importante e, portanto, não interessam. A internalização de tal mensagem pode ter proporções trágicas. Lembrome de uma história particularmente comovente de uma menina negra que tinha apenas cinco anos de idade que, um dia, quando sua mãe foi buscá-la na escola, se recusou a segurar a sua mão. Quando perguntou a ela sobre a razão de sua recusa, a garotinha respondeu: "Eu não te amo, você é negra". Em outras palavras, a escola coloca as crianças negras contra si mesmas, a ponto de criar uma separação emocional entre as elas e aqueles que lhes são semelhantes, 
incluindo seus próprios pais... Que tragédia! Ter vergonha de sua mãe em uma idade tão jovem, onde é completamente vulnerável e incapaz de se defender contra os ataques psicológicos cruéis da dominação branca só pode deixar profundas marcas psicológicas que vão assombrar a criança por toda sua vida e complicar seu relacionamento com ela mesma, sua mãe, e os outros negros de uma forma geral.

Um número considerável de pais que entrevistei no curso da minha pesquisa expressou sua profunda insatisfação com essa abordagem muito problemática da nossa história. $\mathrm{O}$ que é apresentado às crianças negras nos Estados Unidos é na melhor das hipóteses uma caricatura grotesca de sua história, tomando sempre como ponto de partida a escravidão, como se os africanos imigrados contra a sua vontade não tivessem história antes de chegar na América. A história africana é, portanto, severamente truncada, e as crianças negras são retratadas como "descendentes de escravos", uma identidade que não pode realmente ser uma fonte de orgulho ou inspiração, especialmente porque a resistência à escravidão nunca é realmente mencionada, exceto talvez para falar sobre Nat Turner apresentado como um grande criminoso que teve a audácia de organizar uma rebelião responsável pela morte de 6o pobres brancos inocentes... Os pais negros estão justamente se opondo a esta historiografia eurocêntrica humilhante que domina os programas de educação escolar americana. Em alguns casos, as crianças são convidadas a escrever um ensaio sobre os benefícios da escravidão para os negros! Isto é um verdadeiro insulto. (Note-se que nunca ocorreria a esses professores pedir a crianças judias que considerassem que o extermínio de seus antepassados na Alemanha pode ter sido benéfico de alguma maneira).

Eles também protestam contra o fato de que as contribuições dos brancos são muitas vezes exageradas ou francamente falsas, uma vez que os brancos nunca hesitaram em atribuir paternidade e maternidade a tudo o que é belo e forte, mesmo que sejam outros povos que tenham criado essas coisas. Eles não hesitam, por exemplo, em imprimir livros didáticos em que os antigos egípcios têm a pele branca e olhos azuis com o objetivo de atribuir aos brancos a construção das pirâmides e templos de Kemet, e da pujante civilização que suporta esses edifícios. Também não é problema para eles continuarem a falar do "milagre grego" e declararem que inventaram a escrita, a matemática, a filosofia, a religião, etc. mesmo que não seja verdade. Em outras palavras, longe de serem objetivos, os currículos escolares servem como uma ferramenta deliberada e sistemática para a propaganda pró-branca.

Esses pais negros estão preocupados com o impacto psicológico dessas omissões e mentiras para seus filhos. Eles estão particularmente preocupados que seus filhos, submetidos a esta propaganda escolar, teriam necessariamente uma autoestima muito baixa que iria impedi-los de perceber o seu potencial, porque eles sempre duvidariam de suas habilidades intelectuais. Eles também duvidariam das habilidades de outros negros, e estariam mais propensos a confiar em pessoas brancas do que em suas irmãs e irmãos negros. 
Eles não desejam que seus filhos se identifiquem com brancos, assimilem a sua visão de mundo, transformando-se, em última análise, em pequenos brancos. Uma das mães retratou a escola como uma "máquina de moer a cultura infantil", a fim de deixá-la em conformidade com o modelo branco. Outra mãe insistiu que a escola utiliza todas as maneiras possíveis para "despersonalizar" as crianças negras, para branquear a sua consciência ao máximo e fazêlas adotar "óculos brancos", mesmo sem perceber. Quando, por exemplo, uma criança negra sonha em ir a Paris ver a Torre Eiffel. Por que ela não sonha em ir para o continente africano, Egito ou Zimbábue para admirar o que seus antepassados construíram e que permanece inigualável até hoje? Ela entenderia que a Torre Eiffel é, na melhor das hipóteses, uma piada agradável comparada com o que os africanos como ela construíram. Mas é que sonhamos o sonho dos brancos, porque a escola lhes fornece o acesso ao nosso imaginário, e permite que as fantasias brancas invadam nossa consciência a ponto de tomarmos essas fantasias como nossas, em vez de buscarmos a nós mesmos. É por isso que as crianças haitianas sempre aprendem que há quatro estações no Haiti. Estamos mentalmente colonizados, e nos afastamos de nós mesmos - a escola desempenha um papel importante neste processo de colonização e deslocamento mental. Muitos pais negros estão cientes deste perigo e desejam proteger tanto quanto possível a integridade psíquica de seus filhos, a fim de lhes permitir desenvolver uma personalidade cultural em sintonia com sua história e biologia.
Nos Estados Unidos, 86\% dos professores em escolas públicas são brancos. $85 \%$ desses professores brancos são mulheres. Isto cria uma situação particularmente preocupante aos olhos de muitos pais negros que não querem que seus filhos aprendam desde a mais tenra idade a perceber os brancos como figuras de autoridade, e pensar-se como subordinados a eles. É sabido que as crianças pequenas procuram agradar seus pais e outros adultos em posição de autoridade sobre eles. Alguns até se apaixonam por sua professora... Quando a senhora em questão é branca, pode deixar sequelas sérias na mente da criança negra. Isso também pode, naturalmente, contribuir para criar um cisma emocional entre a casa, onde a mãe é negra, e a escola onde a professora é branca. Os pais de meninos eram particularmente sensíveis a esta questão. Uma das mães me explicou que ela não queria que seus filhos "aprendessem com uma mulher branca o que significa ser um homem negro". Outra mãe também não queria que seus filhos "colocassem uma mulher branca em um pedestal."

Alguns pais negros também não querem que os professores brancos tenham autoridade sobre seus filhos e abusem dessa autoridade para puni-los injustamente porque são negros. Esta é uma preocupação extremamente legítima quando consideramos as injustiças flagrantes sofridas por um grande número de crianças negras nas escolas americanas.

A partir dos anos 1980, novas medidas disciplinares intransigentes foram adotadas nas escolas públicas americanas, criando uma realidade muito difícil para muitos jovens. Na verdade, em nome de uma 
política de "tolerância zero", câmeras de vigilância, detectores de metais, buscas, prisões e encaminhamentos para o sistema judiciário tornaram-se comuns em muitas escolas, com agentes de segurança muito visíveis e ativos. Isso resultou em um aumento dramático no número de intimações judiciais, prisões escolares e expulsões (relatório UCLA), embora o número de crimes cometidos por estudantes não tenha aumentado.

Mas como isso não é realmente surpreendente, é claro que a punição escolar está sendo usada de forma racista e discriminatória e afeta crianças melanizadas de modo desproporcional, especialmente afroamericanos e latinos. Um relatório recente publicado pela União Civil da Liberdade de Nova Iorque revela que "os melhores indicadores demográficos para crianças expulsas da escola não são o tipo ou a severidade do crime cometido, mas a cor de sua pele." Outros fatores, como por exemplo, serem colocados em classes para "crianças problemáticas", bem como a escola que frequentam, também afetam suas chances de serem expulsos da escola e intimados para o tribunal. Embora os estudantes negros representem, aproximadamente, $12 \%$ dos alunos, eles respondem por $34 \%$ de todos os encaminhamentos escolares em nível nacional. De acordo com um relatório publicado pelo Departamento de Direito da Pobreza do Sul (2010), os estudantes negros têm três vezes mais chances de serem expulsos do que os estudantes brancos, e quatro vezes do que meninas brancas.

De fato, as severas punições infligidas às crianças negras nas escolas constituem-se como um dos principais mecanismos implementados no âmbito da parceria entre escola e prisões. As infrações menores são usadas como pretexto para introduzir um grande número de jovens no sistema de justiça criminal, a fim de abastecer o complexo industrial penitenciário americano em plena expansão nos últimos anos. Ter um registro criminal, especialmente em uma idade jovem, pode simplesmente inviabilizar a possibilidade de candidatar-se para a admissão em uma universidade, solicitar uma bolsa de estudos, candidatar-se a um emprego, ou mesmo a moradia social. Além disso, conforme indica o relatório recente da IDEA de UCLA, um número elevado de suspensões e de expulsões levam a taxas mais elevadas do abandono, abrindo as portas para uma série de problemas, tais como o desemprego crônico, gravidez precoce, incapacidade de formar e sustentar uma família, e, possivelmente, encarceramento (Sum \& al., 2009). Em outras palavras, muitos jovens negros estão presos de uma forma cínica e cruel em um sistema racista que os condena a um círculo vicioso de pobreza, analfabetismo, delinquência e frustração pessoal.

É surpreendente, neste contexto, que cada vez mais pais negros decidam não confiar neste sistema racista e iníquo, e se recusem a confiar os seus filhos a ele? Aqui estamos lidando com o que chamei em outro lugar "protecionismo racial". Isso é um imperativo dada a implacável guerra racial que é travada contra nós que faz de nossas crianças as primeiras vítimas.

\section{Laços da família}

Há um consenso de que a família americana tem, há várias décadas, enfrenta- 
do uma grave desestruturação (Berk, 2005; Wooding, 2005; Kehily, 2010). O enfraquecimento das relações entre pais e filhos é de particular preocupação e relevância. Esse enfraquecimento é atribuído a vários fatores. O primeiro desses fatores é a redução na quantidade de tempo que os pais passam com seus filhos. Confrontados com as crescentes demandas de seus trabalhos, os baixos salários e a precariedade do emprego, $\mathrm{o}$ aumento do endividamento ou simplesmente motivados pela ganância, os pais americanos trabalham cada vez mais horas ao longo da semana. Em média, os trabalhadores americanos trabalham hoje 163 horas mais por ano do que em 1969, um mês adicional de trabalho por ano (Hewlett \& West, 2005), e é claro que eles estão menos presentes em casa. Esta falta de uma presença constante dos pais deixa um vazio que é inevitavelmente preenchido por outros agentes socializadores, como mídia eletrônica e amigos (reais e virtuais).

De fato, o segundo fator comumente citado nas discussões sobre a desestruturação da família é a dependência das crianças dos meios eletrônicos, tais como a televisão e os videogames. "As crianças americanas gastam uma média de seis horas e 32 minutos por dia usando mídias eletrônicas", observa De Gaetano (2005, p. 89). O problema, acrescenta, é que as mídias eletrônicas são profundamente violentas e utiliza constantemente expressões de "ódio, raiva, vingança e brutalidade" e, finalmente, produzem "atitudes antissociais e muitas vezes extremamente perturbadoras em crianças" (p. 90). De fato, a exposição prolongada e constante à violência dos meios eletrônicos tem sido associada ao comportamento agressivo e violento das crianças, bem como aos seus problemas cognitivos (Kirsh, 2012; De Gaetano, 2005).

O terceiro fator mencionado, embora muito menos freqüentemente, a fim de explicar o enfraquecimento da instituição familiar é a própria escola. Embora a crítica à escolarização não seja nova (por exemplo, Illich, 1971), foi retomada mais vigorosamente nos últimos anos por Gatto (2006), que argumenta que um dos principais objetivos da escolaridade obrigatória foi a ruptura dos laços familiares e da lealdade às famílias, permitindo ao Estado substituir a família como principal agente socializador para as crianças. O desafio era formar, por meio da engenharia social, indivíduos capazes de funcionar efetivamente e aceitar a nova ordem industrial, baseada no individualismo, materialismo, sexismo e racismo. Para isso, foram adotadas leis no final do século XIX e início do século XX para obrigar os pais a entregarem seus filhos a escolas cujo papel era fazer emergir certas atitudes e formar novos comportamentos compatíveis com a vida industrial. As escolas, explica Gatto, "operam como prisões de segurança máxima. A razão pela qual essas instituições nasceram era estabilizar a ordem social e formar as fileiras" (Gatto, 2006, p. 256). O mesmo autor também observa que "as escolas constroem a riqueza nacional destruindo a soberania, a moralidade e a vida familiar" (Gatto, 2006, p. 151-2).

Quer se concorde, ou não, com a opinião perturbadora de Gatto sobre a função da escolarização, é claro que o fato de subtrair as crianças muito cedo da presença e influência de suas famílias cinco dias por semana, sete horas ou mais, em um edifício 
onde estarão sob a influência e a autoridade de estranhos perfeitos só pode minar profundamente a capacidade dos pais para estabelecer laços emocionais muito fortes com seus filhos e para moldar as crenças e atitudes deles. Não só as crianças estão sujeitas a um currículo escolar explícito e oculto que os pais podem desaprovar ou ignorar, mas eles também terão que lidar com a influência ou abuso de outras crianças. Dado o que foi dito acima sobre tendências violentas e a atual desconexão emocional entre muitos jovens, para não mencionar a sua hipersexualização devido a propagandas altamente eróticas, não é surpreendente que a influência de seus pares pode não ser necessariamente um fator sempre positivo. No entanto, quanto mais os pais estão ausentes da vida de seus filhos, mais seus pares estão presentes (Berk, 2005).

No fim das contas, encontramo-nos com uma situação angustiante para as famílias e crianças na América, eloquentemente ilustrada por alguns indicadores, como o aumento acentuado do uso de drogas entre os jovens, da taxa de suicídio entre os adolescentes, da obesidade em crianças, os mais de 20 milhões crimes cometidos anualmente por crianças, etc. A verdade é que os pais são cada vez menos capazes de proteger eficazmente os seus filhos de forças sociais destrutivas. Muitos estudos sugerem que este fracasso é, em grande parte, devido à falta de conexão profunda entre os pais $\mathrm{e}$ seus filhos. (por exemplo, Cheng, Y. et al., 2009; Sieving, R. et al. 2000; Eberhart, N. K. \& Hammen, C. L. 2006). Embora eles vivam sob o mesmo teto, realmente não se conhecem. As crianças americanas falam uma média de 11 minutos com a mãe, e 7 minutos com o pai todos os dias!

Minhas conversas com os pais negros, que optaram por educar seus filhos em casa, a fim de fortalecer suas famílias e protegê-los dos efeitos das forças externas prejudiciais, especialmente da escola, geralmente revelam uma consciência aguda da deterioração da vida familiar americana e do impacto particularmente devastador de tal estado de coisas nas crianças em particular. As questões levantadas por estes pais são profundas: questionam a contribuição da escola para esta desagregação familiar, problematizando não somente as exigências colocadas pela escola sobre a vida da família, em particular o tempo de apropriação das crianças, mas também os valores adquiridos pelas crianças durante a sua escolaridade, e em geral, os objetivos políticos da própria escolaridade, bem como o seu impacto sobre as famílias negras em particular.

\section{Apropriação do tempo das crianças}

Kwaku, um pai e antigo professor me disse o que ele tinha observado:

Você vê, quando vai para a escola, você vai para a escola por oito horas, então você se distancia um do outro, então a mãe e o pai trabalham e fazem todo o tipo de coisas. Você sabe, você é uma família, mas você realmente não se liga; Você não está realmente se conectando, e isso é o que provoca um monte de problemas emocionais que as crianças enfrentam na escola - porque eu os ensinei - todos eles têm esses problemas na escola. 
Ao tempo gasto no recinto físico de uma escola, é necessário acrescentar o tempo nada insignificante que as crianças devem dedicar ao seu dever quando voltam para casa. Duas horas de lição de casa para crianças do jardim de infância ou lição de casa que não os estudantes do $\mathrm{CM}_{2}$ não terminam antes das dez ou onze horas da noite são comuns. Isso, naturalmente, é uma fonte de frustração palpável para muitos pais e desempenha um papel decisivo na decisão de educar seus filhos em casa. Este certamente foi o meu caso. Abena, mãe de três filhos em Nova York, explicou sua frustração nestes termos: "não há tempo para a vida familiar após a lição de casa, porque já é tarde demais e eles têm que ir para a cama para conseguir levantar cedo para ir para a escola no dia seguinte. Isso nunca acaba. "

\section{Socialização: pais e escolas em competi- ção}

Dado que as crianças gastam muito tempo na escola, espera-se que elas sejam profundamente influenciadas pelo que estão expostas. Muitos dos pais entrevistados me disseram que estavam cientes do fato de que a escola, como instituição, competia com eles para influenciar seus filhos. Eles expressaram relutância em entregar seus filhos à escola, preferindo permanecer mestres de sua educação. "Eu quero ter uma grande influência sobre os meus filhos. Eu quero moldá-los ", Carol me confiou," um desejo expresso por Janice: "Eu não quero mais ninguém para criar o meu filho. Quero que ele veja o mundo como eu. Eu não quero que ele adote uma visão de si mesmo que eu não quero que ele tenha. "Havia duas áreas particularmente problemáticas para os pais: a hipersexualização das crianças em idade escolar e uma socialização racial muito negativa.

\section{Um questionamento dos objetivos da escolaridade e o seu impacto nos laços familiares}

Obviamente, os pais entrevistados no decorrer da minha pesquisa estavam muito preocupados com o impacto da escolaridade na capacidade da família de criar laços fortes - esse medo os incentivou a optar pela educação domiciliar. Eles explicaram que a escolaridade reduziu o papel dos pais ao de meros provedores financeiros e supervisores de trabalhos de casa, enquanto usurpam seu papel como a principal fonte de influência sobre seus filhos. Para muitos pais, este não foi o efeito fortuito de um sistema deficiente, mas sim o resultado de um plano cuidadosamente elaborado. Nesse sentido, a escolarização foi redefinida como um mecanismo cujo objetivo, como diz um dos pais, é "tornar as crianças escravas, preparar trabalhadores para o sistema e enfraquecer as famílias.” Julia, mãe de três filhos em Chicago, resumiu as coisas assim: "E você sabe, todas essas escolas são basicamente projetadas para criar força de trabalho para as empresas. É disso que se trata. Treinar as pessoas para seguir ordens é quebrar sua lealdade a suas famílias e seu destino. E não é isso que eu quero para os meus filhos."

Joe compartilha esse ponto de vista: Então por que estamos fazendo a escola em casa? Porque quando nós mandamos nossos filhos para a escola... a escola faz o 
que deve fazer, ou seja, dividir a nossa família e deseducar nossos filhos.

Além disso, alguns destes pais identificam a escola como o principal local de reprodução das injustiças raciais. As más condições físicas de muitos edifícios escolares, a superlotação das salas de aula, as exigências mínimas dos professores para estudantes negros, opções acadêmicas limitadas, vigilância policial constante - todos esses fatores têm o efeito de reduzir as ambições das crianças negras, fazendo-as entender que o esperado é que elas não cheguem a lugar nenhum na vida. Ecoando a farta literatura sobre este assunto (Wacquant, 2001; NYCLU, 2010, por exemplo), muitos pais estavam particularmente preocupados com a criminalização de crianças negras, seu condicionamento e preparação para a vida na prisão. Eles também explicaram como a criminalização de seus filhos na escola criou estresse e tensão insuportável em casa e até mesmo ameaçou a sobrevivência de suas famílias. Malaika descreve sua atmosfera familiar quando ela era constantemente chamada pela escola por causa do “comportamento agressivo' de seus filhos de 7 e 9 anos:

Nós estávamos em guerra... Meu marido e eu estávamos em guerra com as crianças, você sabe o que eu quero dizer? Destruiu-os, destruiume, destruiu o meu marido. E se não há nenhuma família, como você pode lidar com o racismo e a segurança, bem como a educação e a cultura, se a família estiver desestruturada, você sabe?

É evidente que os pais entrevistados não concordaram com a expectativa de um fracasso de seus filhos, nem viram a criminalização deles com bons olhos.

\section{A qualidade da educação}

A educação americana, há muito tempo tem experimentado um mal-estar persistente devido ao descontentamento geral sobre o estado do sistema de educação pública, pelo menos desde 1983, quando um relatório (encomendado pelo então Presidente dos Estados Unidos) Uma Nação em Perigo soou o alarme sobre o que ele considerava uma séria deterioração na educação americana. Citando comparações com estudantes de outros países, o analfabetismo funcional significativo entre adultos e adolescentes, o declínio no bom desempenho dos alunos em exames padronizados, bem como o fato de que cada vez mais alunos do primeiro ano serem obrigados a fazer cursos de nivelamento antes que possam frequentar cursos universitários, os autores do relatório lamentaram que os objetivos básicos da escolarização, os requisitos e a disciplina necessária para atingir essas metas foram perdidas de vista.

Como resultado desta avaliação alarmante, foram propostos muitos planos de ação, como Lei Para a Melhoria da Escola na América (1994) ou a Lei dos Objetivos de 2000 (1994). No entanto, este movimento de reforma escolar culminou com a lei de 2001 Nenhuma Criança Deixada Para Trás (No Children Left Behind - NCLB). Este novo plano tinha como objetivo capacitar as escolas e professores para melhorar o desempenho acadêmico dos alunos, especialmente os estudantes pobres e de cor. Seu objetivo principal era a leitura, escrita e domínio da matemática. Todas as escolas tiveram que 
aplicar anualmente exames padronizados de leitura, matemática e ciências aos seus alunos para determinar o seu progresso e as ações necessárias para garanti-lo em caso de fracasso. Todos os Estados que receberam fundos federais tiveram que provar que todas as crianças tinham atingido suas metas mínimas de leitura e matemática até 2014.

No entanto, apesar das medidas drásticas tomadas no âmbito da NCLB, as questões levantadas no relatório 1983, Uma Nação em Perigo, ainda persistem. Por exemplo, os Estados Unidos ainda estão muito atrás de outros países industrializados, especialmente no nível secundário, e um número relativamente pequeno de alunos têm habilidades avançadas em matemática, leitura e ciências (NECS 2011). Além disso, a taxa de evasão escolar do secundário é preocupante, já que 30\% destes saem sem diploma (Soares et al., 20o8, p. 18). Pior ainda, um número crescente de estudantes que se matriculam na universidade ainda precisa fazer cursos de nivelamento, enquanto é cada vez mais dito e repetido que um diploma universitário já não representa qualquer garantia de habilidades básicas, uma vez que na verdade se pode observar um declínio real na alfabetização de graduados (Soares, 2008). Esta dificuldade dos estudantes americanos para melhorar foi atribuída em parte por alguns investigadores às deficiências persistentes da educação primária e secundária americana, apesar de vários anos de NCLB (Soares et al., 2008; Shellings Report, 2007). Além disso, muitos criticaram o próprio NCLB por prejudicar a qualidade do ensino, insistindo demais em testes padronizados à custa de um ensino de qualidade.

\section{Educação afro-americana: uma situação perturbadora}

Confrontados com os efeitos combinados do racismo passado e do presente e dos desafios materiais, psicológicos e sociais excessivos que o racismo criou e continua a criar, os estudantes negros sofrem ainda mais com os efeitos deletérios de um sistema educacional em declínio. De fato, muitos estudos confirmam que, embora tenham sido feitos progressos modestos nos últimos anos, o desempenho acadêmico dos africanos nos Estados Unidos tende a ser muito inferior do que a já deficiente média nacional (Rothstein, 2004). Além disso, a taxa de evasão dos negros é de 50\% em todo o país e, em algumas áreas urbanas, como Chicago, 61\% (Barton, 2006). Nossas dificuldades nos Estados Unidos não são novas, longe disso, já que desde o início a escolarização tem sido usada contra nós como um poderoso mecanismo de dominação e controle social e racial (Anderson, 1988; Hilliard, 1997; Lomotey, 2010). Hoje, os estudantes afro-americanos, especialmente os mais pobres, frequentam escolas onde a segregação racial prevalece cada vez mais (Frankenberg et al., 2003); os professores designados para estas escolas são sistematicamente menos qualificados, muitas vezes incapazes ou relutantes em fornecer apoio social e emocional ou exigir que façam o seu melhor. Além disso, os professores enviados para escolas secundárias negras estão mudando constantemente, e não necessariamente ensinam sua disciplina de especialização. Por exemplo, um professor especiali- 
zado em matemática pode ter que ensinar história ou gramática inglesa. Podemos facilmente imaginar o resultado! (Donovan et al, 2002; Persell, 2012). E a reclamação de Carter G. Woodson em 1933, que os estudantes negros eram "mal-educados", porque na escola eles foram ensinados "a admirar o hebraico, grego, latim e teutônico e desprezar o que é africano", ainda é válida. $\mathrm{Na}$ verdade, as escolas americanas tendem a se concentrar na Europa, considerada a norma natural para todos. A cultura e o pensamento europeus são implicitamente apresentados como universais, e a Europa como o único local de origem possível de grandes ideias e descobertas (Asante, 2003; Mazama, 2003). Tal experiência está longe de ser ideal para crianças negras, cuja cultura e história são amplamente tornadas invisíveis e insignificantes. Como resultado, as crianças negras muitas vezes permanecem totalmente ignorantes de sua história e cultura, e na opinião de diversos pesquisadores negros, não podem conseqüentemente ser consideradas verdadeiramente educadas (Hilliard, 1997; Asante, 2007). Além disso, não só a maioria dos programas escolares só tratam superficialmente (no melhor dos casos) a experiência cultural e histórica afroamericana, mas também é ausente uma pedagogia adaptada à cultura das crianças negras. Um bom professor deve ser capaz de adaptar seu estilo de ensino à bagagem cultural de seus alunos (Ladson-Billings, 1995). No entanto, os programas de formação de professores são considerados completamente inadequados a este respeito e amplamente responsabilizados pela "incapacidade de os professores ensinar efetivamente os es- tudantes afro-americanos" (Ladson-Billings, 2000, p. 208).

Em vista de tudo o que acaba de ser dito, não é surpreendente que cada vez mais pais negros, frustrados por escolas cuja qualidade tem sido seria e constantemente questionada, e por um sistema que tende a tratar seus filhos sempre como cidadãos da segunda classe, escolham educar seus filhos em casa, a fim de criar uma alternativa melhor.

\section{Os Programas de Estudo}

Muitos pais questionaram os currículos escolares por razões filosóficas e culturais. No nível filosófico, três grandes lacunas foram identificadas. Primeiro, os currículos escolares não estimulam as crianças intelectualmente, mas, de fato, tornam o aprendizado chato: como os programas de educação são determinados principalmente por adultos, as crianças não têm direito a um capítulo sobre o que elas gostariam de estudar. Por outro lado, muitos pais, adeptos de uma teoria de aprendizagem na qual as crianças aprendem mais sobre o que estão interessadas do que o que lhes é imposto por adultos, estão questionando currículos escolares projetados para atender aos interesses adultos (Jones, 1994). Em segundo lugar, os currículos escolares não são suficientemente desafiadores intelectualmente e, portanto, não permitem que as crianças desenvolvam plenamente o seu potencial intelectual. Vários pais me disseram que poderiam ensinar em algumas semanas o que as escolas não podiam ensinam em meses. Assim, para muitos, ir para a escola foi ou seria realmente uma pura perda de tempo. 
Em terceiro lugar, muitos pais expressaram sua profunda insatisfação em relação à concepção muito reducionista e inflexível da educação que está subjacente a maioria dos currículos escolares. Por exemplo, os pais queixaram-se da exclusão de línguas estrangeiras, geografia, ou da aquisição de habilidades práticas. Devido a essa estreiteza, a escolarização não pode produzir indivíduos bem equilibrados. Em vez disso, produz indivíduos sem senso de missão, sem compreender o mundo ao seu redor e seu lugar neste mundo.

No plano cultural, o currículo é considerado culpado de um monoculturalismo e etnocentrismo simplesmente inaceitável. De fato, a experiência cultural e histórica dos brancos funciona como norma universal. Como resultado, as contribuições das pessoas com melanina são deixadas de lado, o que empobrece os currículos escolares. Esta exclusão tem uma dimensão mais angustiante e premente para as crianças negras cujas experiências não estão incluídas nas conversas em sala de aula e por isso se sentem deslocadas, como atesta a afirmação de Marilyn, mãe de três crianças em Washington, DC: "Eu nunca esquecerei, um dia que estava na aula falando sobre as contribuições que outros grupos fizeram à civilização e havia somente um parágrafo sobre os negros como escravos, e eu senti que eu era menos do que nada. Foi terrível. Eu certamente não quero que meus filhos passem por esta experiência. "

Essa questão de inclusão e relevância cultural e histórica foi identificada por muitos pais como um dos principais componentes da educação de qualidade. Eles se opuseram categoricamente à ideia de que al- guém poderia ser considerado educado, permanecendo ignorante de si mesmo, de sua cultura e sua história. "Nossos filhos, explicou uma das mães, não são bemeducados, você sabe. Sua experiência e desempenho são horríveis. Eles não são educados. Há uma diferença entre escolaridade e educação, e a educação está preparando você para a vida. Se você não sabe quem você é, você pode se considerar educado? Você está pronto para a vida?"

$\mathrm{Na}$ verdade, muitos acreditam que a educação adequada deve permitir que as crianças negras desenvolvam uma autoconsciência forte e positiva. A transmissão do conhecimento sobre as realizações e feitos dos negros incutiria em seus filhos um senso de orgulho e direção que será útil para eles mais tarde. Os pais acreditam que isso dará a seus filhos a coragem e a confiança necessárias para superar os obstáculos que enfrentarão como negros em um mundo racista.

\section{Os Professores}

De um modo geral, os professores são criticados por sua falta de erudição, paixão, e às vezes por sua incompetência pura e simples. Os pais também foram particularmente críticos do que eles perceberam como uma falta de compromisso por parte dos professores brancos para garantir que seus alunos negros progredissem adequadamente, e a tendência desses professores para minimizar o potencial intelectual das crianças negras. Isto está em consonância com os estudos que, de fato, sugerem que os professores brancos frequentemente exibem atitudes e comportamentos impertinentes e problemáticos para com os alunos 
negros, que tratam como sendo intelectualmente inferiores e potenciais criminosos (Kunjunfu, 2002; Hilliard, 1997).

\section{Os métodos de instrução}

Muitos dos pais negros que optaram por não enviar seus filhos para a escola consideram que o fato de que a educação pública coloca tanta ênfase em exames padronizados e um mínimo, em vez de sucesso máximo, opõe-se, de fato, a uma aprendizagem real e sustentável. As crianças simplesmente precisam memorizar os dados e cuspi-los para fazer o exame. As crianças não aprendem a pensar ou aprender por si mesmas. De acordo com uma das mães que eu entrevistei: "meu filho foi para a escola pública durante seus anos de secundário e ele basicamente não aprendeu nada. Eu não queria que minha filha tivesse o mesmo destino".

Em conclusão, portanto, as entrevistas realizadas como parte do meu estudo sobre a educação domiciliar na comunidade afro-americana mostram que os pais negros sentem a necessidade de proteger seus filhos e suas famílias das notórias injustiças da escola, e da sociedade racista, capitalista e sexista que as produziu.

Na verdade, o racismo branco interfere de uma forma profunda e destrutiva na capacidade das crianças negras desenvolver autoestima e autoconfiança - e isso, os pais insistem, tem um impacto negativo sobre o seu desempenho e o seu bem-estar geral. Os preconceitos racistas e ações racistas por professores brancos que compõem a grande maioria do corpo docente nos Estados Unidos, bem como programas educacionais etnocêntricos, sempre concentrados nas experiências dos brancos como se fossem a de todo mundo, foram as duas principais fontes de queixa quando se trata de racismo na escola. Este racismo, latente ou explícito, impede que as crianças negras se beneficiem da socialização racial positiva, muito pelo contrário. A isso, se acrescenta a hipersexualização de crianças que, muito jovens, sob a influência da mídia, mas também de seus colegas, tornam-se preocupados com o sexo. Isso leva a comportamentos e obsessões considerados totalmente inadequados e prejudiciais para um desenvolvimento psicológico saudável.

Além de currículos escolares etnocêntricos, professores racistas, a influência problemática de outros alunos; o monopólio que a escola se arroga de grande parte do tempo de seus filhos e suas famílias também é fonte de grande insatisfação para muitos pais que chegaram à conclusão de que o objetivo da escola era, de fato, enfraquecer a influência dos pais, a fim de permitir que o estado se posicione como o principal agente de socialização das crianças. A escolaridade obrigatória permite, afinal, aqueles que dirigem o sistema ter pleno acesso aos cérebros e corações das crianças, para ensinar o que lhes convém para proteger o status quo racial e social.

A educação domiciliar permite que os pais protejam seus filhos, pelo menos em parte, ensinando-lhes o que julgam necessário. Um compromisso significativo sustentado com a experiência cultural e histórica afro-americana muitas vezes ocupa um lugar central na educação prestada aos seus filhos. É a capacidade das crianças negras de adquirirem o autoconhecimento, com base em sua valorização e conhecimento de sua cultura e história, a fim de capacitá-los a 
desenvolver uma forte autoestima e autoconfiança. $\mathrm{O}$ objetivo final é permitir que seus filhos se beneficiem de uma forte e positiva socialização racial e cultural, a fim de reduzir o impacto potencialmente devastador do racismo.

Outro benefício imensurável da educação domiciliar é, naturalmente, a quantidade de tempo disponível, permitindo que os pais, filhos e irmãos estabeleçam laços emocionais profundos. Este tempo compartilhado é o que finalmente torna todo o resto possível. Os pais que eu entrevistei eram bastante irônicos sobre o fato de os adultos que praticam a educação domiciliar serem acusados de isolacionismo e criticados por escolher proteger seus filhos de influências externas nefastas (Medlin, 200o). Eles insistiram que era, de fato, exatamente o que era necessário: aconselhar e proteger seus des- cendentes de influências sociais e psicológicas prejudiciais. Os pais que não fazem isso às vezes são julgados severamente, como negligentes e maus pais, que não levam suas responsabilidades seriamente o suficiente e permitem que seus filhos sejam destruídos, sob seus próprios olhos indefesos.

Na verdade, a educação domiciliar é a mais recente estratégia usada pelos africanos nos Estados Unidos para contornar os obstáculos colocados em nosso caminho, a fim de nos impedir de viver de melhor forma possível. Nossa luta nos Estados Unidos para garantir a melhor educação possível para nossos filhos tem uma longa e rica história que nos honra. Longe de ser indiferente ao destino de nossos filhos, como alguns gostam de repetir, continuamos a fazer enormes esforços para garantir que eles possam desfrutar de uma existência decente, apesar do racismo e outras forças maléficas.

\section{Referências}

ANDERSON, J. The education of Blacks in the South, 1860-1935. Chapel Hill and London: The University of North Carolina Press, 1988.

ASANTE, Molefi K. Afrocentricity. Trenton: Africa World Press, 2003

An Afrocentric Manifesto. London: Polity Press, 2007

BARTON, P. The dropout problem: Losing ground. Educational Leadership. 63 (5), 20o6, p. 14-18.

BERK, L. Why parenting matters. In: Childhood Lost. How American Culture is Failing Our Kids. S. Olfman (ed). Westport, Conn.: Praeger, 2005, p. 19-53.

CHADWICK, C. Seven minutes a day: the modern-day excuse for a parent. Disponível em: http://www.thenational.ae/thenationalconversation/comment/seven-minutes-a-day-themodern-day-excuse-for-a-parent\#ixzz2JeNfFbPo, 2011. Acesso em:

CHENG, Y., Tao, M., Riley, L., Kann, L., Ye, L., Tian, X., \& Chen, D. Protective factors relating to decreased risks of adolescent suicidal behavior. Child Care Health and Development, 35, 2009, p. 313-322. 
DE GAETANO, G. The impact of media violence on developing minds and hearts. In: Childhood Lost. How American Culture is Failing Our Kids. S. Olfman (ed). Westport, Conn.: Praeger, 2005, p. 89-106.

DONOVAN, M. \& Cross, C. (Eds.). Minority students in special and gifted education. Washington: National Academy Press, 2002.

EBERHART, N. K. \& Hammen, C. L. Interpersonal predictors of onset of depression during the transition to adulthood. Personal Relationships, 13 (2), 2006, p. 195-208.

FEAGIN, J. Racist America: roots, current realities, and future reparations. New York: Routledge, 2010.

FRANKENBERG, E., Chungmei, L. \& Orfield, G. A Multiracial Society with Segregated Schools: Are We Losing the Dream? The Civil Rights Project Harvard University, 2003.

GATTO, J. The Underground History of American Education. New York: The Oxford Village Press, 2006.

HEWLETT, S. \& West, C. The War against Parents. In: Childhood Lost. How American Culture is Failing Our Kids. S. Olfman (ed). Westport, Conn.: Praeger, 2005, p. 57-87.

HILLIARD, A. III. (1997). Teacher education from an African American perspective. In: J. Jordan Irvine (Ed.). Critical knowledge for diverse teachers \& learners. Washington: American Association of Colleges for Teacher Education, 1997, p. 125-148.

ILLICH, I. Deschooling Society. NY: Harper \& Row, 1971.

INGERSOLL, R. Out-of-field teaching, educational inequality, and the organization of schools. (Research Report \# R-02-1). Center for the Study of Teaching and Policy. University of Washington, Seattle, 2002.

JOHNSON, H. The American dream and the power of wealth: Choosing schools and inheriting inequality in the Land of Opportunity. New York: Routledge, 2006.

JONES, E. \& Nimmo, J. Emergent Curriculum. Washington DC: NAEYC, 1994.

KEHILY, M. Childhood in crisis? Tracing the contours of 'crisis' and its impact upon contemporary parenting practices. Media, Culture \& Society, Volume 32, Issue 2, 2010, p. 171185.

KIRSH, STEVEN. Children, adolescents, and media violence: a critical look at the research. Thousand Oaks: Sage, 2012.

KUNJUFU, K. Black students-white middle-class teachers. Chicago: African American Images, 2002.

LADSON-BILLINGS, G. J. The dreamkeepers: successful teachers of African-American children. San Francisco, CA: Jossey-Bass, 1997. 
LADSON-BILLINGS, G. Fighting for our lives. Preparing teachers to teach African American students. Journal of Teacher Education. Vol 51, 3, 2000, p. 206-214.

LOMOTEY, K. (Ed.). Encyclopedia of African American Education. 2 volumes. Thousand Oaks: Sage Publications, 2010.

MAZAMA, A. (Ed.). (2003). The Afrocentric paradigm. Trenton: Africa World Press, 2003.

MAZAMA, A. \& Musumunu, G. African American Homeschooling: Motivations, Challenges and Opportunities. New York: Routledge, 2015

MEDLIN, R. Homeschooling and the question of socialization. Peabody Journal of Education, 75:1-2, 2000, p. 107-123.

NYCLU Report. (2010). School to prison pipeline. Available at Disponível em: http://www.nyclu.org/issues/youth-and-student-rights/school-prison-pipeline. 2011. Acesso em:

PERSELL, C. How race and education are related. Schools and Society. A Sociological Approach to Education. J. Ballantine \& J. Spade (eds). $4^{\text {th }}$ edition. Thousand Oaks: Sage, 2012, p. 311-320.

ROTHSTEIN, R. The achievement gap: A broader perspective. Educational Leadership, 61(3), 2004, p. 193-195.

SOARES, L. \& Mazzeo, C. College-Ready Students, Student-Ready Colleges. An Agenda for Improving Degree Completion in Postsecondary Education. Center for American Progress. 2008.

WACQUANT, L. Deadly symbiosis: When ghetto and prison meet and mesh. Punishment and Society, 3, 2011, p. 95-133.

Recebido em: 05/06/2019

Aprovado em: 31/10/2019 